CREAM Current Research in Environmental \& Applied Mycology 6 (3): 150-158(2016) ISSN 2229-2225

www.creamjournal.org

Article

CREAM

Copyright (C) 2016

Doi 10.5943/cream/6/3/1

Online Edition

\title{
Variation in conidiophore complexity in Aspergillus versicolor
}

\author{
Khalil AMA \\ ${ }^{1}$ Botany and Microbiology Department, Faculty of Science, Al-Azhar University, Cairo, Postal Code 13759, Egypt. \\ khalilahmed_1980@hotmail.com
}

Khalil AMA 2016 - Variation in conidiophore complexity in Aspergillus versicolor. Current Research in Environmental \& Applied Mycology 6(3), 150-149, Doi 10.5943/cream/6/3/1

\begin{abstract}
Aspergillus versicolor is an abundant species and habitually isolated from soil, plant debris, saline water environments, and indoor air environments. Cultural, macroscopic and microscopic features including ontogenesis process of Aspergillus versicolor (NRRL 238) were monitored. Fluorescence and scanning electron microscopies were used to investigate the development of conidiophore and the process of conidium formation. Ontogeny of phialides in Aspergillus and Penicillium conidiophores were studied. Although, simultaneous production of phialides are confined to Aspergillus conidiophores and considered unique feature to Aspergillus species, former studies observed fragmentary heads resembling penicillate fructifications in Aspergills section versicolor. Our results revealed that, $A$. versicolor has ability to produce successive phialides separately such as those in Penicillium species and produce proper Penicillium conidiophore with monoverticillate structure besides Aspergillus conidiophore. This study designated to defines the development of Penicillium and Aspergillus conidiophores within A. versicolor as a member of section Versicolor.
\end{abstract}

Key words - Aspergillus versicolor - conidiophore - ontogeny - scanning electron microscope

\section{Introduction}

The last complete monograph of Aspergillus was written in 1965 (Raper \& Fennell 1965). They recognised 132 species and 18 varieties. Additional taxonomic and nomenclatural works have been carried out by Samson \& Gams (1985). Aspergillus is one of the most economically important genera of filamentous fungi (Samson et al. 2011). Therefore, it is important to consider any taxonomic changes in order to keep the taxonomic system practical for economic and regulatory reasons. This has been accomplished through open discussion and consensus-building in meetings such as the Aspergillus Workshops, and in efforts such as the lists of accepted species and synonyms (Pitt et al. 2000; Samson et al. 2011). Raper \& Fennell (1965) revised the genus Aspergillus and accepted 18 species in the $A$. versicolor group. Aspergillus versicolor (Vuillemin) Tiraboschi is the most broadly described species in section Versicolor (Jurjevic Z. et al. 2012). It has been isolated from soil (Domsch et al. 1980), indoor environments (Samson et al. 2001, 2010, Engelhart et al. 2002, Shelton et al. 2002, Amend et al. 2010, Anderson et al. 2011), numerous foods and feeds (Pitt \& Hocking 2009), hyper-saline water (Kis-Papo et al. 2003, Mbata 2008), and related with many health problems of humans and animals Jussila 2003, Perri et al. 2005, Baddley et al. 2009, Edmondson et al. 2009, Pitt \& Hocking 2009, Moreno \& Arenas 2010). It is a producer of the mycotoxin sterigmatocystin that is a precursor of aflatoxin B1 (Mills \& Abramson 1986, Tuomi et al. 2000, Nielsen 2003, Veršilovskis \& Saeger 2010). Aspergillus is hyphomycetous which are characterised by, the formation of conidiophores with large, 
heavy walled stipes and swollen apices termed vesicles (Pitt \& Hocking 2009). Vesicles are usually roughly spherical, but are elongated or less conspicuously swollen in a few species. Vesicles bear crowded phialides, or metulae and phialides, which are characteristically all borne simultaneously (Pitt \& Hocking 2009). Conidium development in Penicillium resembles Aspergillus, but the morphological arrangement of the conidiophore structures differs (Alexopoulos et al. 1996). Phialide production in Penicillium and related genera is always successive, not simultaneous (Pitt \& Hocking 2009). The presence of immature metulae or phialides all at the same stage of development indicates Aspergillus; structures with some phialides producing conidia while one or more others are still developing indicates Penicillium or a related genus (Pitt \& Hocking 2009).To delineate Aspergillus from other related genera such as Penicillim, Smith (1969) and Pitt and Hocking (1985), considered that the simultaneous production of phialides and the presence of foot cells on conidiophore were absolute criteria for Aspergillus species. Some previous studies find that fragmentary heads resembling penicillate fructifications were commonly observed in Aspergills section versicolor (Jurjevic Z. et al. 2012). This paper aimed to study the development of penicillate-like strcture in A. versicolor beside Aspergillus conidiophore.

\section{Materials \& Methods}

\section{Organism}

Organism used in the course of this study was Aspergillus versicolor (NRRL 238). The organism was obtained from the Culture Collection of school of Pharmacy and Bio-molecular science, Liverpool John Moores University, United Kingdom.

\section{Culture Media}

Cultures were grown on Czapek yeast extract agar (CYA), malt extract agar (MEA) and potato dextrose agar (PDA) at $28{ }^{\circ} \mathrm{C}$ for 10 days in darkness. Colony diameters and appearance were recorded and photographed.

\section{Microscopy}

\section{Bright field microscope}

Microscopic examination was performed by tearing apart a small amount of mycelium in a drop of $0.1 \%$ lacto-phenol blue or by a modified cover slip culture method (Nugent et al. 2006) and examining the preparation under bright field microscopy fitted with camera and Differential Interference Contrast (DIC) light microscopy with an Olympus $\mathrm{BH} 2$ research microscope using $\mathrm{x} 40$ and x60. Images were captured by Camera (INFINITY 1) and were analysed by Infinity Analyse software provided with measurement functions and image enhancement options.

\section{Fluorescent microscope}

The fluorescent stain Calcofluor White (CFW) (W/V) was used to observe the young conidia, scars and septa (Romero \& Minter 1988) using a solution of calcofluor 17352 (Polysciences, Washington, PA) with fluorescent brightener 28.F6259 (Sigma, St. Louis, MO). Samples were examined using an Olympus BX51 fluorescence microscope with appropriate filters. The stain CFW was exited at $412 \mathrm{~nm}$ and emitted at $347 \mathrm{~nm}$. Images were captured by digital camera (HAMAMATSU) ORCA-ER C742-95 and were analysed by OPENLAB 4.0.2. soft-ware provided with measurement function and image enhancement option.

\section{Scanning electron microscope}

For examination by scanning Electron Microscopy, small sections from the fresh culture of $A$. versicolor were fixed in $2.5 \%$ Glutaraldehyde for 20 minutes to provide a rapid inter and intra-cellular penetration. The fixed specimens were dehydrated through a series of increasing concentrations of ethanol, ending in a 100\% dehydrating liquid of the highest possible purity. Typically these are steps of 
$10,20,30,50,70,90,95,100 \%$ at 10 minutes for each, with 3 changes at $100 \%$. Acetone was used as the intermediate fluid because it is miscible with carbon dioxide. Critical point drying (CPD) was used to prevent collapse in ESEM. This is achieved by replacing acetone with liquid $\mathrm{CO} 2$ and then the liquid $\mathrm{CO} 2$ is taken to a critical temperature and pressure $\left(34.5^{\circ} \mathrm{C}\right.$ and $1200 \mathrm{psi}$ (pounds per square inch)). At these parameters, the shearing forces and surface tension on the samples are minimal and the $\mathrm{CO} 2$ is in equilibrium between liquid and gas. This stops the samples collapsing whilst they are dried. The samples were sputter-coated with gold using an Emitech K550X coating unit. The coated specimens were then loaded into FEI (Quanta 200) ESEM (Environmental Scanning Electron Microscopy, 2008) and observed over a range of magnifications. Images were obtained using an image capture system (Oxford Instruments, INCA system, Oxford, UK). Another method used for examination of living cells was a low-temperature environmental scanning electron microscopy (ESEM). Specimens were rapidly frozen in liquid nitrogen slush (at $-180{ }^{\circ} \mathrm{C}$ ) under vacuum and transferred to the Cryo-preparation chamber, where the frozen samples were sublimated at $-80{ }^{\circ} \mathrm{C}$ to remove surface ice crystals. Samples were then re-cooled to $-130{ }^{\circ} \mathrm{C}$ and sputter coated with gold in the preparation chamber using a voltage of $1.2 \mathrm{kV}$ Specimens were viewed at an accelerating voltage of $5 \mathrm{kV}$ at $-130{ }^{\circ} \mathrm{C}$ with a FEI Quanta 200 ESEM fitted with a Quorum Technology Cryo-preservation system. Images for all methods were obtained using an image capture system (Oxford Instruments, INCA system, Oxford, UK).

\section{Results}

\section{Description of Aspergillus versicolor (NRRL 238) on different media}

Colonies grown 10 days on CYA at $28{ }^{\circ} \mathrm{C}$ attained $21-28 \mathrm{~mm}$ diam., sulcate, centrally raised 4 $5 \mathrm{~mm}$, sporulating well, conidial heads pale greyish green near tea green, central area mealy from aggregated aerial hyphae, exudate present in mostly clear to pale pink shades (brownish red in one isolate), faint to very obvious pinkish soluble pigment, reverse vinaceous or brown or scarlet. Colonies grown 10 days on MEA at $28{ }^{\circ} \mathrm{C}$ attained $25-32 \mathrm{~mm}$ diam., low, with funicular hyphal aggregates, sometimes dominating colony appearance, sporulating in pale to dark bluish green to grey green colour, no exudate seen, soluble pigment yellow in some isolates, not present in others, reverse pale yellow, yellow orange or orange. Colonies grown 10 days on PDA at $28{ }^{\circ} \mathrm{C}$ attaining $18-28 \mathrm{~mm}$ diam., centrally raised, often good sporulating, either consisting of a dense felt of conidiophores or of aerial and closely interwoven mycelium bearing the conidiophores. Colour at first white, then changing to yellow, orange-yellow to yellow-green, often intermixed with flesh to pink colours, reverse pale yellow, yellow orange or orange. In most culture media conidiophores including stipes hyaline or slightly pigmented, smooth-walled, (45-) 200-750(-1050) $\times(4-) 5-8(-12) \mu \mathrm{m}$. Vesicles subglobose to ellipsoidal, or pyriform to spatulate, $9-17 \mu \mathrm{m}$ in diam. Conidial heads biseriate, metulae covering half to entire vesicle (no single image shows metulae covering just half of the vesicle), 3-6(-9) $\times 2.5-4.5 \mu \mathrm{m}$, Phialides borne on metulae, 5.5-8.0 × 2.5-3.0 $\mu \mathrm{m}$. Metulae 5.0-7.5 $\times 2.0-2.5 \mu \mathrm{m}$. Conidia spherical to sub spherical, occasionally ellipsoidal, (2-) 2.5-3.5(-6.5) $\mu \mathrm{m}$, finely roughened wall (Fig.1).

\section{Aspergillus versicolor conidiophores}

A penicillus like structure is easy to recognize by microscopic examination. After 2-3 days of vegetative growth, vegetative hyphae of $A$. versicolor start to produce very short stalks from nonspecialised cell and at irregular intervals along vegetative hyphae. These so-called stalks can differentiate into conidiophores or stipes. Conidiophore stalk extends about 5-10 $\mu \mathrm{m}$ into the air. During conidiophore extension, the tip swells and forms the phialides one by one. These phialides give rise of mainly uninucleate conidia. A penicillus conidiophores or stipes is characterized by very short, solitary, borne at irregular intervals along vegetative hyphae and no foot cell noticed by microscopy (Figs. $2 \& 3$ ).

The attachment of phialides to a stipe directly as a single whorl or verticillus called monoverticillate. Sometimes phialiedes bear a short chain of conidia, but more commonly a single developing conidium, shed at maturity and succeeded by another blown out terminally from the conidiophore (Fig. 4). Scanning electron microscope showed that the phialide production in Penicillium 


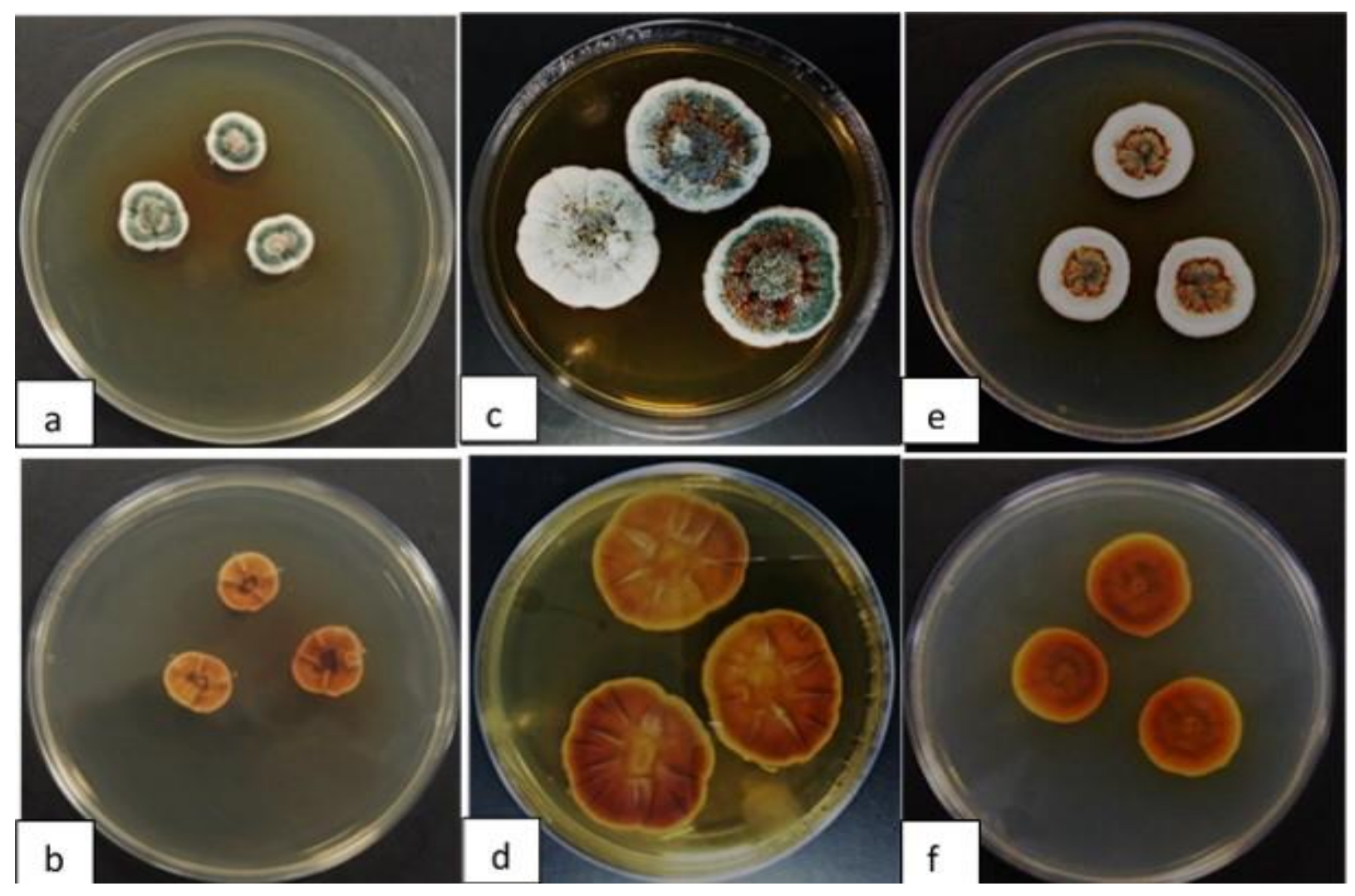

Fig. 1 - Petri dishes are $9 \mathrm{~cm}$ diam., colonies grown at $28{ }^{\circ} \mathrm{C}$ for 10 days. a. CYA colonies. b. CYA colony reverse. c. MEA colonies. d. MEA colony reverse. e. PDA colonies f. PDA colony reverse
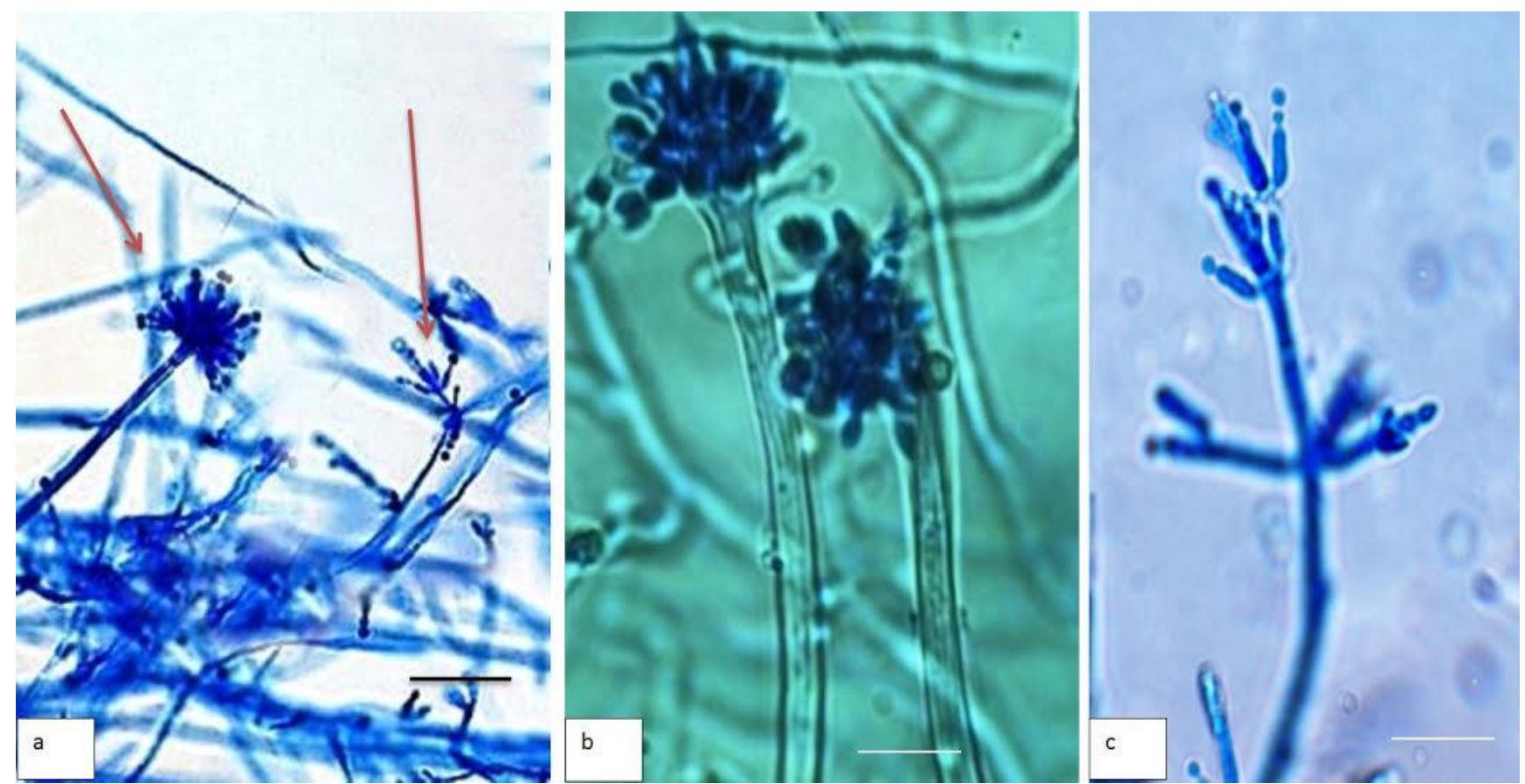

Fig. 2 - Bright field micrographs of Aspergillus versicolor showing. a. Both Aspergillus and Penicillium conidiophores in one spot b Aspergillus conidiophores, subglobose vesicle, smooth stipe and conidia c Penicillium conidiophores from aerial hyphae, phialids and conidia. Bar $=\mathrm{a} .500 \mu \mathrm{m}, \mathrm{b}$. $50 \mu \mathrm{m}$, c. $100 \mu \mathrm{m}$ 

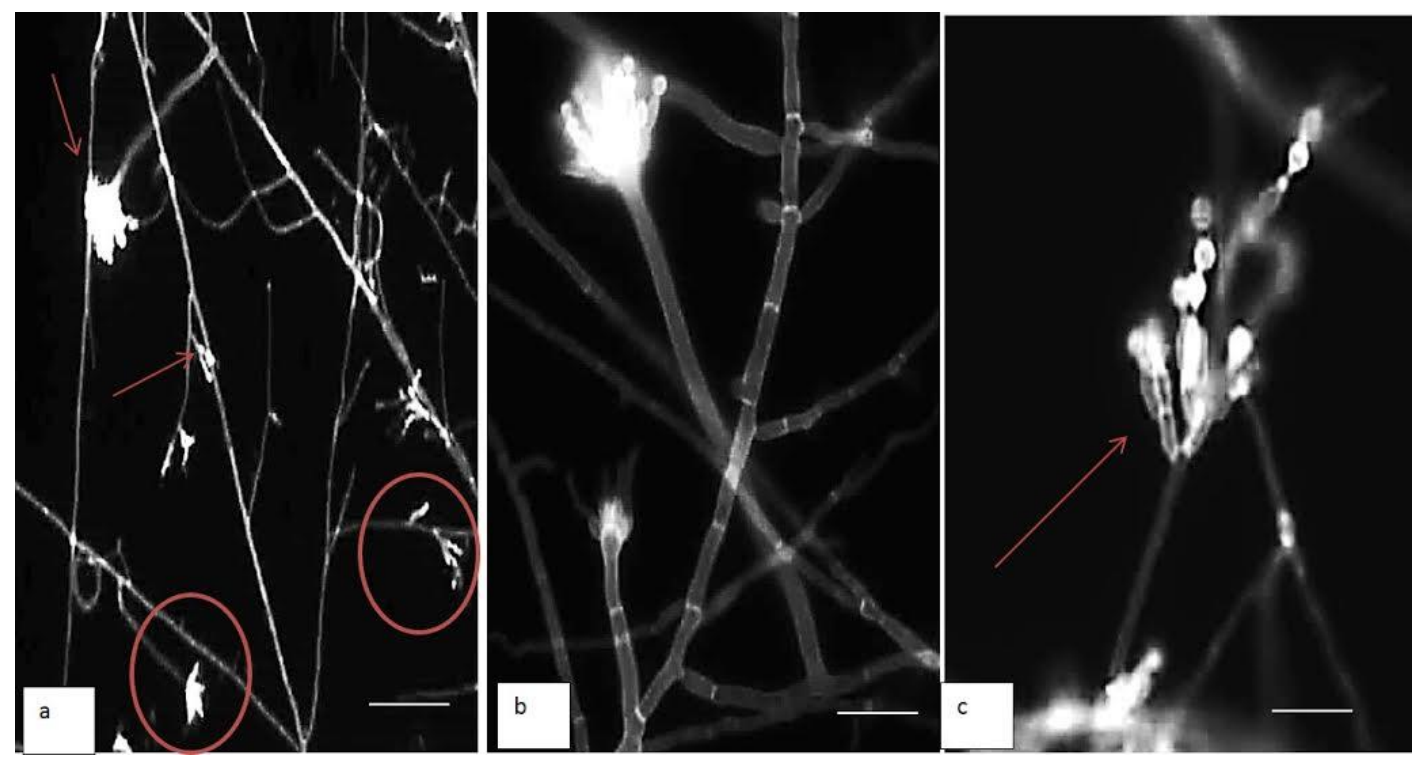

Fig. 3 - Fluorescence micrographs of Aspergillus versicolor showing a. Both Pinicillium and Aspergillus conidiophores (arrowed) in one spot b. Aspergillus conidiophores, non- septate stipe, subglobose vesicle, smooth stipe, phialid, foot cell and conidia. c. Penicillium conidiophores from aerial hyphae, phialids (arrowed) and conidia. $\mathrm{Bar}=$ a. $500 \mu \mathrm{m}, \mathrm{b} .100 \mu \mathrm{m}, \mathrm{c} .40 \mu \mathrm{m}$
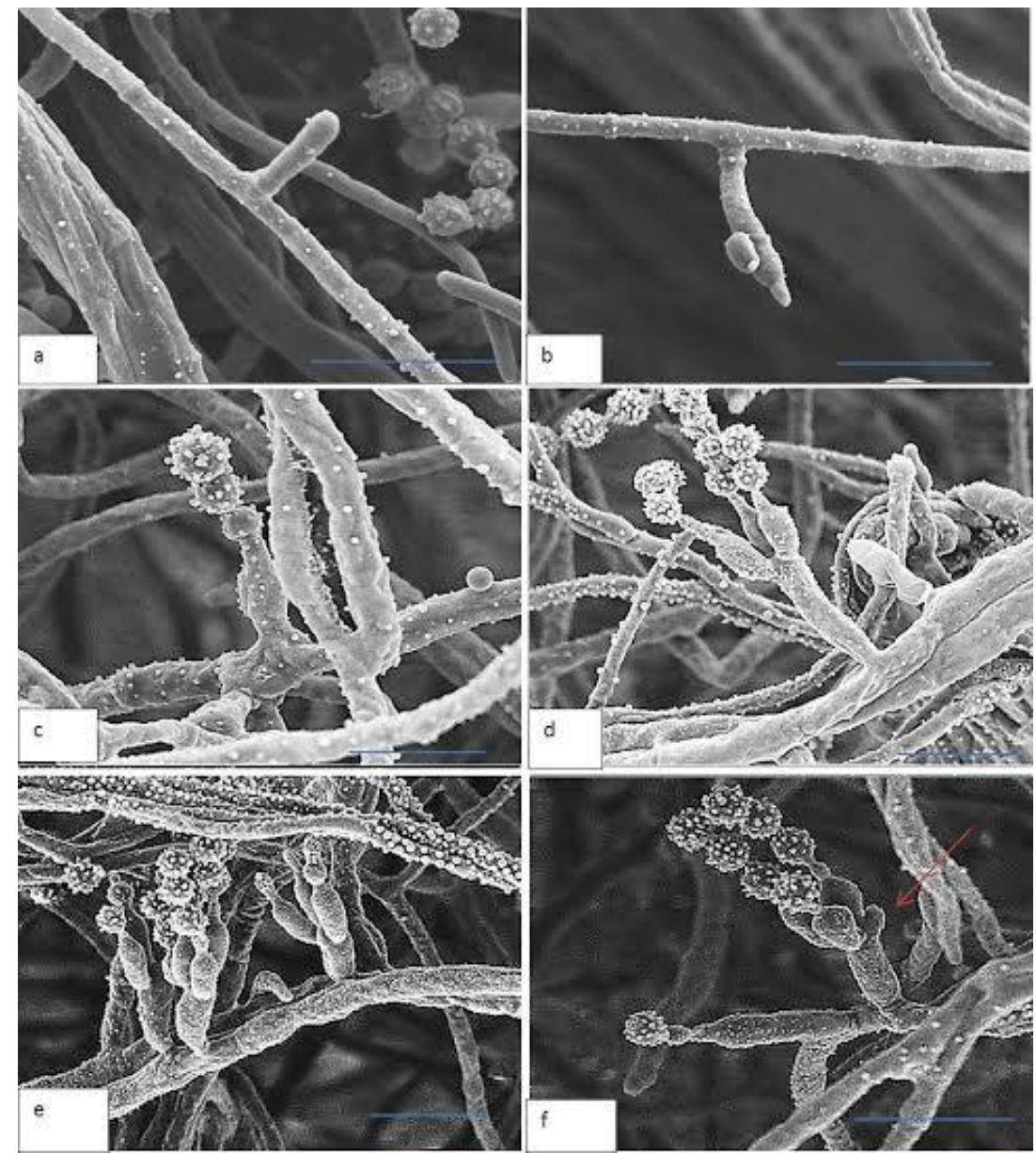

Fig. 4 - Scanning electron micrographs of Aspergillus versicolor showing ontogeny of Penicillium-like conidiophore and conidia $\mathrm{a}-\mathrm{b}$ Pinicillium-like conidiophores raised from vegetative hyphae, very short stipe, and size of stipe is very close to vegetative hyphae. $\mathrm{c}-\mathrm{d}$ phialides attached directly to a stipe e. Penicillium-like structure rose from vegetative hyphae on interval areaes. f. Penicillium-like structure with some phialides and conidia while other phialids are still developing. Bar $=10 \mu \mathrm{m}$ 


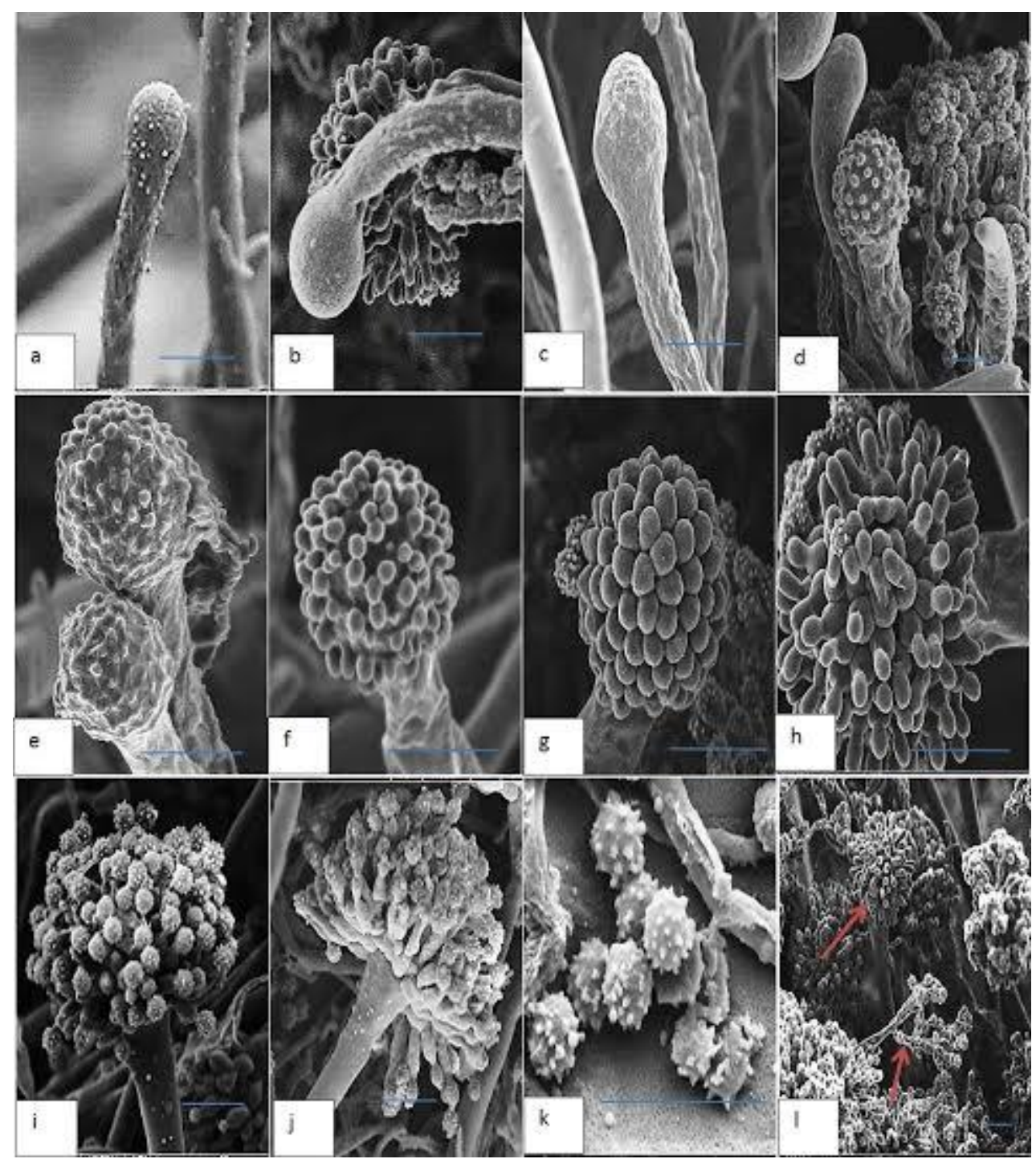

Fig. 5 - Scanning electron micrographs of Aspergillus versicolor showing ontogeny of Aspergillus conidiophore and conidia $\mathrm{a}-\mathrm{j}$ formation of conidiophore and conidial head $\mathrm{k}$. Rough walled conidia 1. Both Aspergillus and Penicillium conidiophores in one spot (arrowed) while the above arrow refer to Aspergillus while the below refer to penicillium structure. Bar $=10 \mu \mathrm{m}$

like structure is successive, not simultaneous. The presence of immature phialides all at the same stage of development as in Aspergillus structure not found. Conidiophore with some phialides producing conidia while one or more other phialids are still developing is very obvious (Fig. 4). Scanning electron microscope showed no difference between conidia produced from both Aspergillus and Penicillium conidiophores. After a period of vegetative growth, air-exposed colonies of A. versicolor form two types of aerial hyphae (Figs. $2 \& 3$ ). One type is quite similar to vegetative hyphae and has a diameter of about $2-3 \mu \mathrm{m}$. The second type of aerial hyphae has a diameter of about 5-6 $\mu \mathrm{m}$. These so-called stalks can differentiate into conidiophores (Fig. 2 \& 3). The conidiophore stalk extends about $200-750$ $\mu \mathrm{m}$ into the air and is formed from a specialised foot-cell within the substrate mycelium. When the stalk has reached its maximum height, the tip swells and forms a vesicle with a diameter of 9-17 $\mu \mathrm{m}$. Vesicles are usually roughly subglobose to pyriform or spatulate. In biseriate A. versicolor, the vesicle surface buds resulting in a layer of primary sterigmata termed metulae. The metulae in turn bud twice. These results in a second layer of sterigmata called phialides. Metulae and phialides are typically borne simultaneously i.e. immature metulae or phialides are all present at the same stage of development. The phialides give rise to chains of mainly uninucleate basipetal conidia. Conidia are spherical to subspherical, occasionally ellipsoidal and finely rough walled (Fig. 5). 


\section{Discussion}

Aspergillus versicolor is the most reported fungal species in section Versicolores from damp indoor environments (Jussila 2003, Rydjord et al. 2005) and its presence is used as an indicator of Sick Building Syndrome (SBS) (Schwab \& Straus 2004). The media components are important criteria for fungal growth, along with important physiological parameters that lead to maximum sporulation in fungi (Kim et al. 2005). In the present investigation, type of culture media and their chemical compositions considerably affected the mycelial growth rate and conidial production in A. versicolor. However, types of culture media had no noticeable affected on conidiophores formation in $A$. versicolor. Aspergillus and Penicillium are clearly revealed in some species such as Aspergillus versicolor group that produce in addition to the typical Aspergillus head, fragmentary heads resembling those of Penicillium (Vanden Bossche et al. 1988). This study showed that, Penicillium heads are produced only during the first days of incubation period. From our point of view, Aspergillus versicolor has a tendency to produce penicillium-like structure at the beginning of incubation period due to spreading purposes. Correspondingly, the production of conidia by monoverticillate Penicillium heads is much faster than its production by Aspergillus heads. In A. versicolor the monoverticillate Penicillium heads produced phialides in successive way while only Aspergillus heads produced simultaneous phialids. Therefore, A. versicolor group cannot be used as an evidence for producing simultaneous phialides by monoverticillate penicillia in contrasting with Vanden-Bossche et al. (1988). In conclusion, $A$. versicolor has ability to produce a true penicillium-like structure with monoverticillte conidiophores rather than fragmentary heads resembling penicillate fructifications. Moreover, There is no doubt of that Aspergillus versicolor belongs to Aspergillus species but the production of Penicillium like structure should be considered and used as a unique morphological character for this species.

\section{Acknowledgements}

I wish to thank the emeritus professor Anthony J.S. Whalley in Liverpool John Moores University for his management and warm welcome during my time in Liverpool and for providing me A. versicolor NRRL 238 which have been used in this work.

\section{References}

Alexopoulos CJ, Mims CW, Blackwell M. 1996 - Introductory Mycology. John Wiley and Sons, New York, New York

Amend AS, Seifert KA, Samson R, Bruns TD. 2010 - Indoor fungal composition is geographically patterned and more diverse in temperate zones than in the tropics. Proceedings of the National Academy of Sciences. 107, 13748-13753.

Anderson B, Frisvad JC, Sondergaard I, Rasmussen IB, Larsen LS. 2011 - Associations between fungal species and water-damaged building materials. Applied and Environmental Microbiology 77, 4180-4188.

Baddley JW, Marr KA, Andes DR, Walsh TJ, Kauffman CA, Kontoyiannis DP, Ito JI, Balajee SA, Pappas PG, Moser SA. 2009 - Patterns of susceptibility of Aspergillus isolates recovered from patients enrolled in the transplant-associated infection surveillance network. Journal of Clinical Microbiology 47, 3271-3275.

Domsch KH, Gams W, Anderson TH. 1980 - Compendium of Soil Fungi. 1st Ed., Academic Press, UK.

Edmondson DA, Barrios CS, Brasel TL, Straus DC, Kurup VP, Fink JN. 2009 - Immune response among patients exposed to molds. International Journal of Molecular Sciences 10, 5471-5484.

Engelhart S, Loock A, Skutlarek D, Sagunski H, Lommel A, Farber H, Exner M. 2002 - Occurrence of toxigenic Aspergillus versicolor isolates and sterigmatocystin in carpet dust from damp indoor environments. Applied and Environmental Microbiology 68, 3886-3890.

Jurjevic Z, Peterson SW, Horn BW. 2012 - Aspergillus section Versicolores: nine new species and multilocus DNA sequence based phylogeny. IMA Fungus 3, 61-81. 
Jussila, J. (2003). Inflammatory Responses in Mice after Intratracheal. Instillation of Microbes Isolated from Moldy Buildings, Helsinki, $\quad$ Finland: National Public Health Institute.

Kim YK, Xiao CL, Rogers JD. 2005 - Influence of culture media and environmental factors on mycelia growth and pycnidial production of Sphaeropsis pyriputrescens. Mycologia 97(1) 2532.

Kis-Papo T, Kirzhner V, Wasser SP, Nevo E. 2003 - Evolution of genomic diversity and sex at extreme environments: fungal life under hyper-saline Dead Sea stress. Proceedings of the National Academy of Sciences, USA 100, 14970-14975.

Mbata TI. 2008 - Isolation of fungi in hyper saline Dead Sea water. Sudanese Journal of Public Health $3,170-172$.

Mills JT, Abramson D. 1986 - Production of sterigmatocystin by isolates of Aspergillus versicolor from western Canadian stored barley and rapeseed canola. Canadian Journal of Plant Pathology $82,151-153$.

Moreno G, Arenas R. 2010 - Other fungi causing onychomycosis. Clinics in Dermatology 28, 160163.

Nielsen KF. 2003 - Mycotoxin production by indoor molds. Fungal Genetics and Biology 39, 103-117.

Nugent LK, Sangvichen Ek, Prakitsin Sihanonth, Nutthaporn Ruchikachorn, Whalley AJS. 2006 - A revised method for the observation of conidiogenous structures in fungi. Mycologist 20, 111114.

Perri P, Campa C, Incorvaia C, Parmeggiani F, Lamberti G, Costagliola C, Sebastian A. 2005 Endogenous Aspergillus versicolor endophthalmitis in an immuno-competent HIV-positive patient. Mycopathologia 160, 259-261.

Pitt JI, Hocking AD. 1985 - Fungi and Food Spoilage, CSIRO Division of Food Research, Academic Press, Sidney.

Pitt JI, Hocking AD. 2009 - Fungi and Food Spoilage. 3rd Ed., London: Springer Verlag.

Pitt JI, Samson RA, Frisvad JC. 2000 - List of accepted species and their teleomorphs in the family Trichocomaceae. In: Integration of Modern Taxonomic Methods for Penicillium and Aspergillus. Samson RA, Pitt JI. Eds. Amsterdam: Harwood Academic Publishers: 9-47.

Raper KB, Fennell DI. 1965 - The Genus Aspergillus. Baltimore: Williams \& Wilkins Company.

Romero AI, Minter DW. 1988 - Fluorescence microscopy: an aid to the elucidation of ascomycete structures. Transactions of the British Mycological Society 90, 457-470.

Rydjord B, Hetlandy G, Wikerz HG. 2005 - Immunoglobulin G antibodies against environmental moulds in a Norwegian healthy population shows a bimodal distribution for Aspergillus versicolor. Scandinavian Journal of Immunology 62, 281-288

Samson RA, Gams W. 1985 - Typification of the species of Aspergillus and associated teleomorphs. In: Advances in Penicillium and Aspergillus Systematics. Samson RA, Pitt JI. Eds. New York: Plenum Press: 143-154.

Samson RA, Houbraken J, Frisvad JC, Thrane U, Andersen B. 2010 - Food and Indoor fungi. CBS Laboratory Manual series 2, 390.

Samson RA, Varga J, Frisvad JC. 2011 - Taxonomic studies on the genus Aspergillus. CBS-KNAW Fungal Biodiversity Centre. Studies in Mycology.

Schwab CJ, Straus DC. 2004 - The roles of Penicillium and Aspergillus in sick building syndrome. Advances in Applied Microbiology 55, 215-238.

Shelton BG, Kirkland KH, Dana W. 2002 - Profiles of airborne fungi in buildings and outdoor environments in the United States. Applied and Environmental Microbiology 68, 1743-1753.

Smith G. 1969 - An Introduction to Industrial Mycology, 6 Ed., Arnold, London.

Tuomi, T, Reijula, K., Johnsson, T., Hemminki, K, Hintikka, E.L., Llindroos, O., Kalso, S., KoukilaKähkölä P, Mussalo-Rauhamaa H, Haahtela T. 2000 - Mycotoxins in crude building materials from water-damaged buildings. Applied and Environmental Microbiology 66, 1899-1904.

Vanden-Bossche H, Mackenzie DWR, Cauwenbergh G. 1988 - Aspergillus and Aspergillosis'. Plenum Press, New York, NY. 
Veršilovskis A, Saeger SD. 2010 - Sterigmatocystin: occurrence in foodstuffs and analytical methods an overview. Molecular Nutrition and Food Research 54, 136-147. 